\section{References}

Bowman, D.M.J.S., et al., 2009: Fire in the Earth System, Science, 324 481-484

Conedera, M., Tinner, W., Neff, C., Meurer, M., Dickens, A.F. and Krebs, P., 2009: Reconstructing past fire regimes: methods, applications, and relevance to fire management and conservation, Quaternary Science Reviews, 28: 555-576.
Flannigan, M.D. Krawchuck, MA de Groot, W. Wotton, BM. and Gowman, L.M., 2009: Implications of changing climate for global wildland fire, International Journal of Wildland Fire, 18 : 483-507

Gavin, D.G., Hallett, D.J., Hu, F.S., Lertzman, K.P., Prichard, S.J., Brown, K.J., Lynch, J.A., Bartlein, P. and Peterson, D.L., 2007: Forest fire and climate change in western North America: insights from sediment charcoal records, Frontiers in Ecology and the Environment, 5: 499-506.
Whitlock, C., Higuera, P.E, McWethy, D.M. and Briles, C.E., 2010: Paleoperspectives on fire ecology: revisiting the fire regime concept, The Open Ecology Journal, 3, 6-23.

For full references please consult:

http://www.pages-igbp.org/products/newsletters/ref2010_2.html

\title{
Recent advances in the analysis and interpretation of sediment-charcoal records
}

\section{Philip E. Higuera ${ }^{1}$, D.G. Gavin ${ }^{2}$, P.D. Henne ${ }^{3}$ and R.F. Kelly}

'Department of Forest Ecology and Biogeosciences, University of Idaho, USA; phiguera@uidaho.edu

${ }^{2}$ Department of Geography, University of Oregon, USA; ${ }^{3}$ Oeschger Center for Climate Change Research and Institute of Plant Sciences, University of Bern, Switzerland; ${ }^{4}$ Department of Plant Biology, University of Illinois, USA

\section{Numerical models and statistical analysis aid interpretation of fire history from sediment-charcoal records, allowing inferences into the causes of past fire-regime shifts through quantitative analyses and data-model comparisons.}

High-resolution charcoal records from lake sediments are an increasingly important proxy for understanding the characteristics and variability of past fire regimes (e.g., Gavin et al., 2007). Recent advances in simulating sediment-charcoal records have improved our understanding of this proxy and help guide data analysis methods. With improved quantitative analyses, comparisons between fire-history records, other paleoenvironmental records and dynamic ecosystem models increasingly enable insights into the causal mechanisms controlling past fire regimes.

\section{Modeling sediment-charcoal records}

The interpretation of fire history from sediment-charcoal records has relied heavily on understanding two sets of processes: (1) Those affecting the charcoal source area, and (2) Those affecting charcoal deposition and burial (taphonomy; e.g., Clark, 1988). Questions of charcoal source area have been addressed through empirical studies (e.g., Clark, 1990; Whitlock and Millspaugh, 1996; Tinner et al., 1998; Gardner and Whitlock, 2001; Lynch et al., 2004) but ultimately assessing source areas requires an appropriate model to simulate charcoal dispersal. Peters and Higuera (2007) expanded the dispersal model used by Clark (1988) and tested its suitability for simulating charcoal dispersal by comparing predictions with data from an experimental canopy fire (Lynch et al., 2004). The dispersal model explained $67 \%$ of the variability in charcoal deposition from 0-200 $\mathrm{m}$ from the edge of the fire, implying that it was an appropriate tool for simulating charcoal records.

Higuera et al. (2007) used this work to develop a numerical model simulating the charcoal deposition in a lake bottom, given dispersal from hypothetical fire histories and mechanisms affecting charcoal taphonomy. The CharSim model, when calibrated to fire regimes from Alaskan boreal forests, generates charcoal stratigraphies that are statistically similar to empirical records (Higuera et al., 2007; Fig. 1). This similarity suggests that the model represents at least one set of processes creating observed sediment-charcoal records and makes it possible to use simulated charcoal records to test conceptual models and inform data analysis methods.

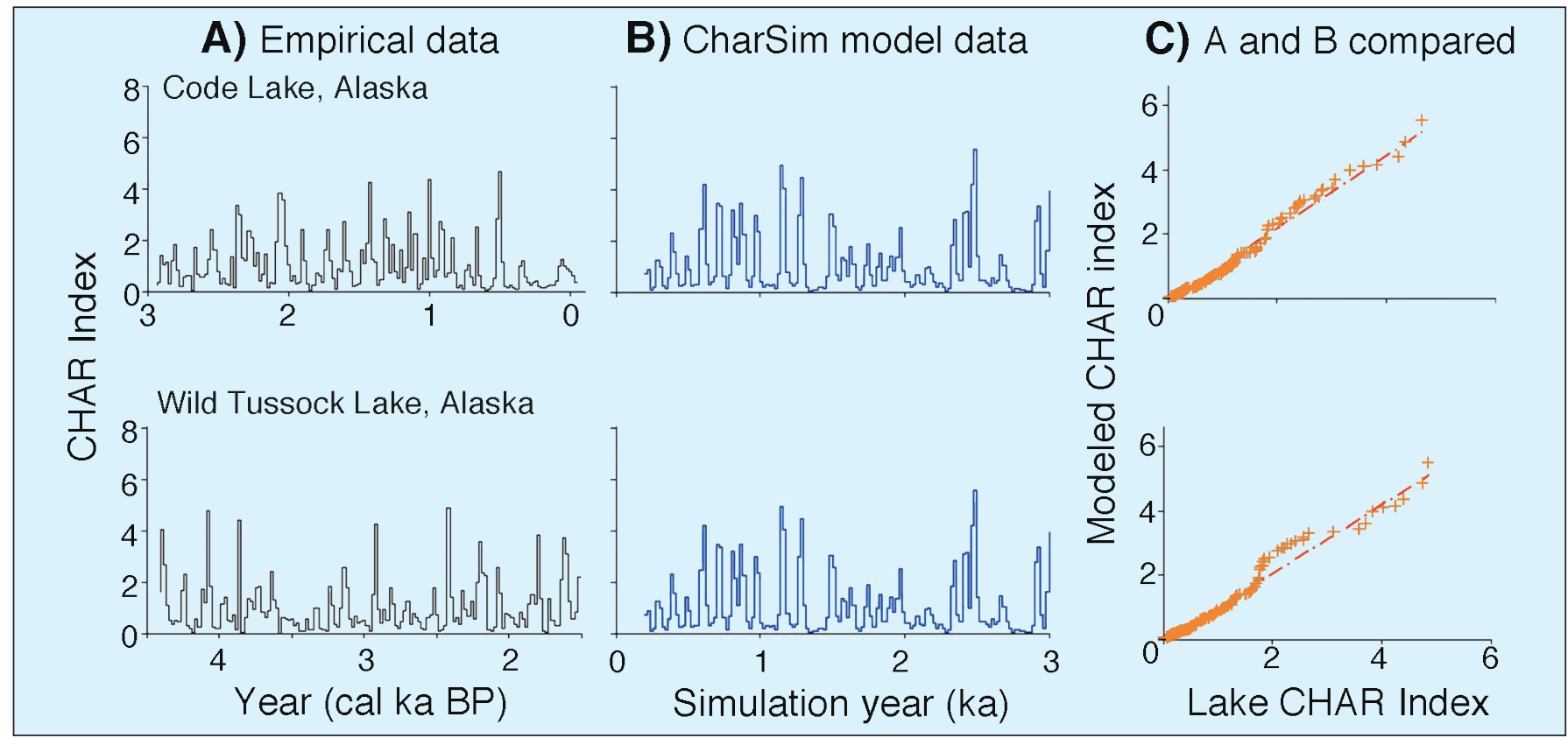

Figure 1: Comparison between (A) empirical charcoal records and (B) a simulated charcoal record from the CharSim model (modified from Higuera et al., 2007) for Code Lake (top row) and Wild Tussock Lake (bottom row), in Alaska. Charcoal accumulation rates (pieces $\mathrm{cm}^{-2} \mathrm{a}^{-1}$ ) in empirical records are standardized to a mean value (CHAR index), allowing direct comparison with the simulated record. Empirical records include only periods that could satisfy the assumption of approximately constant sediment accumulation, mixing and burning rates (explicit in the simulated record). Linear quantile-quantile (Q-Q) plots (C) support visual inspection suggesting similar CHAR distributions between empirical and simulated records. The CharSim records were created using specific, non-varying parameters representing fire frequency, fire size, primary and secondary charcoal transport, sediment mixing, and sediment sampling. The mean fire-return interval (FRI) within 100 m of the simulated lake was 120 a. This is consistent with the mean FRIs of 135 a at Code and Wild Tussock lakes (95\% CI 113-160 and 113-157, respectively) for the past 5.5 ka, inferred from peak detection methods (Higuera et al., 2009). 
Analysis of a series of simulated records suggests that charcoal source areas for macroscopic charcoal (>100 $\mu$ m diameter) are likely larger than previously inferred from experimental data but in agreement with observations during or after fires (within several to $10 \mathrm{~s}$ of $\mathrm{km}$; e.g., Tinner et al., 2006). Distinct charcoal peaks in simulated records also reflect fire events within relatively short distances of a 1-ha simulated lake (i.e., with 500-1000 m; Higuera et al., 2007). This link between charcoal peaks and fire events emerges from the combined effects of charcoal dispersal and the landscape pattern of fire. When fires are large relative to the charcoal source area, distinct peaks are created when fires burn near a lake. These inferences provide important theoretical support for existing and recently developed statistical techniques for analyzing sediment-charcoal records.

\section{Statistical analysis of sediment- charcoal records}

Macroscopic sediment-charcoal records have been analyzed in three distinct ways: interpreting fire episodes from peaks identified in individual records, compositing multiple records to reveal a regional trend, and comparing records to identify the drivers of fire regimes. A common goal with high-resolution macroscopic charcoal stratigraphies is to identify charcoal peaks and interpret them as series of fire episodes occurring near the lake. This task of "peak detection" is accomplished by applying a threshold to the charcoal time series.

Recent advances in peak detection (reviewed in Higuera et al., in press a) include (1) determining whether a macroscopic charcoal stratigraphy is suitable for peak detection in the first place by using a signal-to-noise index (e.g., Kelly et al., 2010); (2) identifying the noise-related variance in a charcoal record as distinct from variance related to fire events; and (3) setting a threshold based on an estimate of noiserelated variance. Although the statistics of peak identification have progressed, it remains important that researchers validate the recent portion of the record with independent evidence of fire.

The proliferation of charcoal records in recent decades motivates the development of regional series by compositing multiple records, akin to the goal of compositing climate reconstructions. Unlike climate proxies, which are calibrated to temperature before compositing, methods for calibrating charcoal records to biomass or area burned are just now being developed (e.g., Higuera et al., in press b). Therefore, compositing requires standard- ization to a common unitless scale before averaging (Marlon et al., 2008, 2009; Power et al., 2008). The resulting charcoal index of inferred biomass burning shows patterns that can be compared with independent proxies of potential fire-regime drivers (e.g., humans, vegetation, and climate; Marlon et al., 2008).

Finally, a careful comparison of closely-spaced charcoal records is a simple means of examining regional controls of fire regimes, thus helping to distinguish between regional drivers (e.g., climate, vegetation and humans) and local, more variable drivers of fire history (e.g., lightning ignitions, fuel loads and weather; Swetnam et al., 1993). Gavin et al. (2006) used this rationale to compare two fire records spanning the past 5 ka located 11 $\mathrm{km}$ apart. Although this period contains only a fraction of the climatic variability of the Holocene, the records showed a longterm, synchronous trend over the past $2 \mathrm{ka}$ (Fig. 2).

\section{Data-model comparisons}

Our improved understanding of sedimentcharcoal records and our ability to extract quantitative fire-history metrics have allowed comparisons between charcoal records and landscape models with complementary spatial and temporal scales.

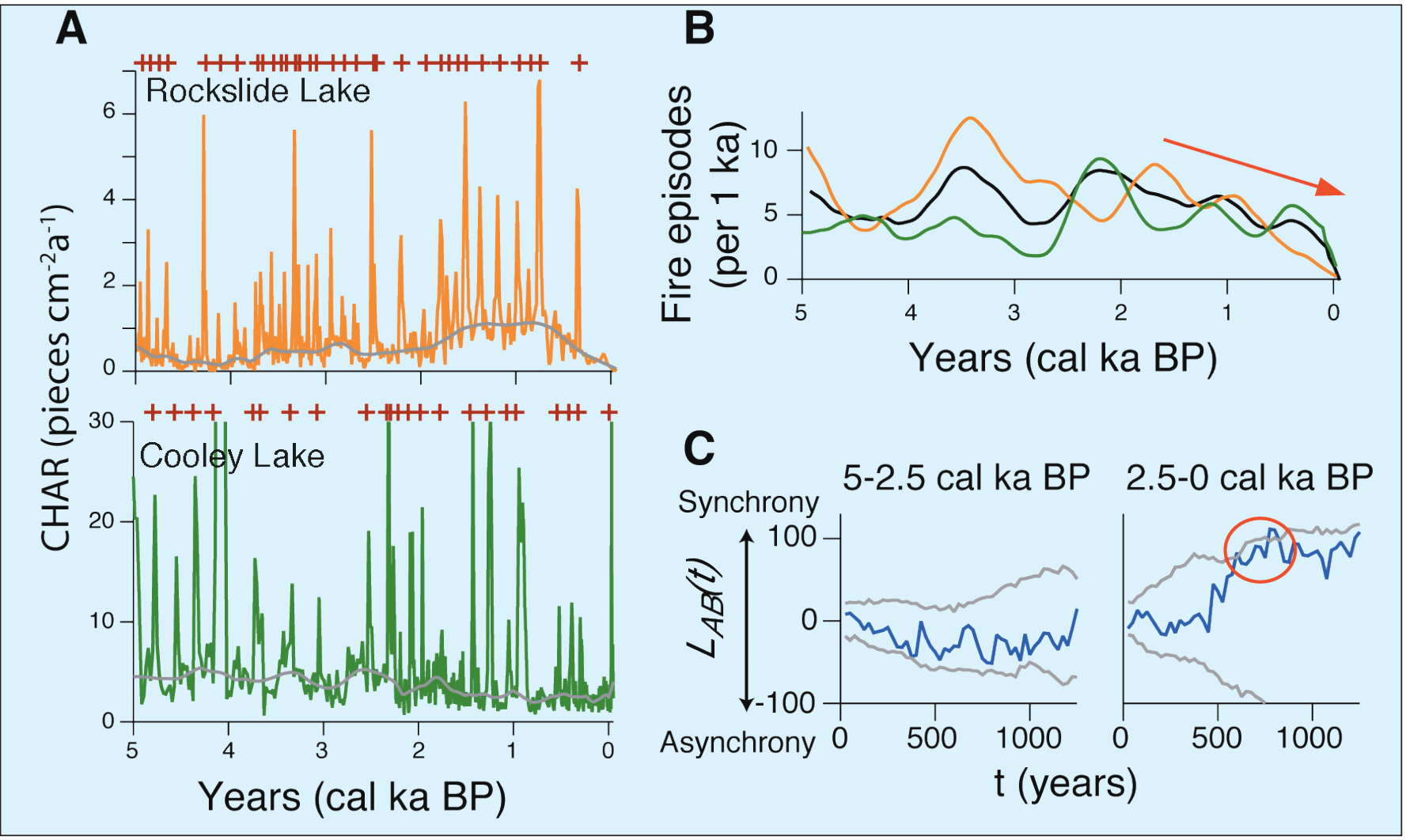

Figure 2: Analysis of charcoal stratigraphies from two lakes $11 \mathrm{~km}$ apart in southeastern British Columbia (from Gavin et al., 2006). A) Charcoal accumulation rate (CHAR) for the past $5 \mathrm{ka}$ in Rockslide Lake (orange) and Cooley Lake (green). Gray line = "background" level from which peak heights are determined. Red crosses indicate inferred fire episodes. B) Smoothed fire frequency (with a 500-a window) shows diverging trends before 2.5 cal ka BP but similar decreasing trends since then. Black line = composite of the Cooley (green) and Rockslide (orange) lake records. Despite the proximity of the two sites, fire-return intervals increased at Rockslide Lake but decreased at Cooley Lake between the two periods. Intervals since $2.5 \mathrm{cal} \mathrm{ka} \mathrm{BP}$ were similar at each site (red arrow). C) Synchrony analysis of the inferred fire episodes based on the Ripley K function (represented by $\left.L_{A B}(t)\right)$ for two $2.5 \mathrm{ka}$-long periods. Gray lines are the $95 \%$ confidence envelope based on 1000 randomizations of shifting the records relative to each other. This analysis shows the temporal scales at which two (or more) records show temporal dependence ("synchrony"). The significance found at scales of 0.6 to 0.8 ka (red circle) is consistent with the timescale of the decreasing trend over this period. The dissimilar fire history from 5-2.5 cal ka BP may represent a less important role for climate during that period. 
Pairing high-resolution charcoal records with landscape models helps overcome an important limitation common to paleorecords: patterns of past change can be reconstructed, but the causal mechanisms responsible are difficult to determine.

Ecological modeling offers the distinct advantage of being able to isolate the interactive influences of climate, vegetation and/or human activity on fire regimes. Statistically comparing simulation output with reconstructed fire history then helps to evaluate competing hypotheses explaining past fire-regime dynamics. Brubaker et al. (2009) employed this approach to suggest that the impact of shifting vegetation was more influential on regional fire regimes in Alaska than the direct effects of climate change. Specifically, in a statistical comparison of charcoal-inferred and simulated fire regimes, a reconstructed increase in fire frequency at ca. $5.5 \mathrm{cal} \mathrm{ka} \mathrm{BP}$ only matched simulations that combined the addition of highly-flammable black spruce with the fire-dampening effects of decreased temperature or increased precipitation.

Data-model comparisons are also instructive when evaluating human impacts on past fire regimes. Using a dynamic landscape vegetation model, Colombaroli et al. (in review) found that ignition frequency overrode climatic influences in determining area burned near the treeline in the Swiss Alps. Thus, an increase in the impact of fire on treeline vegetation during the last 4 ka was attributed to Bronze Age land-use intensification.

\section{Conclusions and future directions}

An improved understanding of sediment-charcoal records through process modeling has helped advance analytical techniques for inferring fire history over thousands of years. In conjunction with a proliferation of high-resolution charcoal records developed over the past several decades, paleofire records are increasingly used to untangle complex interactions between multiple drivers of historic fire regimes. Data-model comparisons in particular have and will continue to play an important role in these efforts. Although we focused here on how these comparisons help improve interpretations of sediment-charcoal records, the benefits of this integration are equally important to model development. Ultimately, landscape and larger-scale models can be validated using sediment records and thus more confidently applied to project fire regimes under anticipated future conditions.

\section{Data}

The empirical charcoal records reported in figures 1-2 are publicly available through the International Multiproxy Paleofire Database: http:// www.ncdc.noaa.gov/paleo/impd/paleofire. html.

\section{References}

Brubaker, L.B., Higuera, P.E., Rupp, T.S., Olson, M., Anderson, P.M. and Hu, F.S., 2009: Linking sediment-charcoal records and ecological modeling to understand causes of fire-regime change in boreal forests, Ecology, 90: 1788-1801.

Colombaroli, D., Henne, P.D., Gobet, E., Kaltenreider, P. and Tinner, W., in review: Species responses to fire, climate, and human impact at tree-line in the Alps as evidenced by paleo-environmental records and dynamic simulation approaches, Journal of Ecology.

Gavin, D.G., Hu, F.S., Lertzman, K. and Corbett, P., 2006: Weak climatic control of stand-scale fire history during the late Holocene, Ecology, 87: 1722-1732.

Higuera, P.E., Peters, M.E., Brubaker, L.B. and Gavin, D.G., 2007: Understanding the origin and analysis of sediment-charcoal records with a simulation model, Quaternary Science Reviews, 26: 17901809

Kelly, R.F., Higuera, P.E., Barrett, C.M. and Hu, F.S., in press: A signalto-noise index to quantify the potential for peak detection in sediment-charcoal records, Quaternary Research.

\title{
Specific molecular markers in ice cores provide large-scale patterns in biomass burning
}

\author{
Natalie Kehrwald ${ }^{1}$, R. Zangrando ${ }^{1}$, A. Gambaro ${ }^{1,2}$, P. Cescon ${ }^{1,2}$ and C. Barbante ${ }^{1,2}$ \\ ${ }^{1}$ Institute for the Dynamics of Environmental Processes, University of Venice, Italy; kehrwald@unive.it \\ Department of Environmental Science, University Ca'Foscari of Venice, Italy
}

\section{Flammable vegetation releases distinct organic markers associated with smoke particles, and the presence of these compounds in ice cores across the globe provide information on changes in fire regimes through time.}

International efforts to retrieve ice cores from both poles and every possible continent have resulted in a wealth of highresolution climatic and environmental records. Methodological advances in measuring past atmospheric chemistry are revealing aerosols from both natural and anthropogenic biomass burning. Chemical markers in ice cores can measure past fire regimes including changes in spatial distribution, timing and fuel type (Conedera et al., 2009). Low-latitude ice cores primarily reflect regional fire and climate parameters, while polar ice cores reflect a global signal. The reconstruction of past wildfire occurrence through molecular markers in ice cores is a new field, one that requires further investigation; nonetheless, the global array of archived ice cores allows for future research into one of the least known aspects of the climate system.
Fire activity has varied in the past in response to climate, vegetation change and human land use. Recent aerosol emissions are a combination of anthropogenic particle emissions (e.g., oils, soot, synthetics) and vegetation burning (Simoneit, 2002). Biomass burning causes carbon dioxide emissions equal to $50 \%$ of those from fossil-fuel combustion and so is also highly likely to influence future climate change (Solomon et al., 2007). Here, we discuss four chemical groups that can be used as proxies for fire-history reconstruction from ice cores: (1) monosaccharide anhydrides (MA), (2) light carbolic acids, (3) polycyclic aromatic hydrocarbons (PAH), and (4) lignin burning products. Combining measurements of these four chemical groups can help determine the relative contributions of natural and anthropogenic emissions on regional and global scales.

\section{Specific molecular tracers in smoke (MA)}

Biomass burning injects particles with distinct signatures of organic matter into smoke and the global atmosphere (Simoneit, 2002). Important compounds from biomass burning include monosaccharide anhydrides (MA), where the most important tracer compound among them is levoglucosan and to a lesser degree galactosan and mannosan. These are specific molecular tracers because they can only be generated by combusting woody tissue at temperatures greater than $300^{\circ} \mathrm{C}$ (Simoneit, 2002). Among MA, levoglucosan has been considered an excellent tracer choice because it is emitted in large quantities and is globally pervasive. Levoglucosan is transported in smoke plumes and returns to the surface by wet and dry deposition. The presence of levoglucosan in ice cores 